\title{
El legado cosmopolita de Michael Handelsman
}

The Cosmopolitan legacy of Michael Handelsman

\author{
Juan Carlos Grijalva
}

Assumption College, Estados Unidos

DOI: https://doi.org/10.32719/13900102.2019.45.2

Fecha de recepción: 28 enero 2019

Fecha de aceptación: 2 abril 2019 


\section{RESUMEN}

Este texto busca explorar el carácter cosmopolita de la crítica de autores ecuatorianos en la obra ensayística de Michael Handelsman. La revalorización de la literatura ecuatoriana, desde una mirada crítica, liberadora y universal, es uno de los aportes fundamentales del crítico norteamericano.

PalABras Clave: Michael Handelsman, crítica, Ecuador, literatura, ensayo.

\section{ABSTRACT}

This text seeks to explore the cosmopolitan character of critiques on Ecuadorian authors in the essayistic works of Michael Handelsman. One of the fundamental contributions of the American critic is revaluating Ecuadorian Literature from a critical, liberating and universal approach.

KEYwORDS: Michael Handelsman, critic, Ecuador, Literature, essay.

El trabajo intelectual de una vida dedicada a la investigación, reflexión y promoción de la literatura y cultura ecuatorianas no puede reducirse a unas pocas palabras de comentario como estas. Quiero pensar que este homenaje a Michael Handelsman no puede limitarse tampoco a una mesa de discusión o incluso a un congreso sobre su obra crítica. No se me entienda mal. Tales reconocimientos son justos y más que merecidos, pero espero que tú mismo estés de acuerdo conmigo, querido Michael, cuando digo que el valor de tu obra crítica está en la lectura de tus textos. Leerte, avivar tu lectura, seguir aprendiendo de ti, discutirte, repensar la investigación y reflexión crítica que nos has dejado y continuarás dejándonos, aquí está el verdadero homenaje. Encuentro que uno de los mayores legados de Michael Handelsman es el de habernos enseñado a ser lectores mucho más curiosos, críticos y apasionados de una producción literaria y cultural que en su aparente "marginalidad" y "pequeñez", goza también plenamente de "centralidad" y "universalidad".

El trabajo crítico-literario-cultural de Michael Handelsman, en efecto, al focalizarse de manera privilegiada sobre el Ecuador, deja abierta la pregunta: ¿̨ómo ser "universal” o "cosmopolita" con una literatura que ha sido enjuiciada de "localista", "provinciana", "pequeña" o "periférica"? ¿Y no ha sido el cosmopolitismo, en cierto sentido, una tradición de fuga de la literatura ecuatoriana que ha llevado, desafortunadamente, a una mirada exótica y abstracta sobre nosotros mismos? El mismo nombre del país, Ecuador, por ejemplo, al buscar identificarse con la línea imaginaria trazada por la expedición geodésica francesa del siglo XVII, aparece como 
una identidad que sustrae al país de sí mismo y prefiere así la denominación neutral, universal, de un cálculo geográfico planetario, al reconocimiento de alguna de sus realidades internas. Son muchas las imágenes frágiles y los escritores que han insistido en la existencia de un Ecuador ajeno, lejano, desconocido o extranjero a sí mismo, el cual es contrastado con la necesidad de reconectarse con la tierra, los antepasados o como diría un conocido danzante popular, el deseo de morir enterrado en una "vasija de barro".

Frente a estas encrucijadas, el trabajo crítico-literario-cultural de $\mathrm{Mi}$ chael reconcilia la valoración de "lo propio" con una mirada "cosmopolita”. En Género, raza y nación en la literatura ecuatoriana: Hacia una lectura decolonial (2011), nuestro autor recopila una selección representativa de su producción crítico-ensayística de los últimos cuarenta años y puntualiza, en tono auto-biográfico, lo relativo de la supuesta "marginalidad" y "pequeñez" de la literatura ecuatoriana frente a la supuesta "universalidad" de las producciones de otros países y sus autores. Michael nos confiesa:

yo me crié en Nueva Jersey -el Norte- y el Mississippi de los años 20 y 30 del siglo pasado me resultaba muy lejos, muy anticuado y muy "pequeño"... curiosamente, no fue hasta años después, cuando había descubierto en castellano a Juan Rulfo, y su Pedro Páramo y El llano en llamas, que pude comprender lo arbitrario y perjudicial de los esquemas imperiales y coloniales: es decir, yo, de EEUU, tuve que viajar primero a Comala y conocerla en castellano antes de apreciar a Faulkner... el punto que espero resaltar es la absoluta centralidad -por no decir universalidad- de lo que para muchos es "local", "pequeño", "menor", "periférico", "marginal". Primero Comala y, luego, Ecuador me han sacado de mi encierro cultural para, así, conocer realmente al mundo" (6).

El primer trabajo crítico del joven postulante a doctor en literatura, en la Universidad de Florida, en 1976, no fue, en efecto, un estudio de la novelística de William Faulkner o Juan Rulfo, sino una investigación que buscaba arrojar nuevas luces sobre varias escritoras ecuatorianas desconocidas del siglo XX. Amazonas y Artistas: Un estudio de la prosa de la mujer ecuatoriana, tesis de doctorado dirigida por el gran crítico del modernismo Ivan Schulman, fue publicada en dos tomos por la Casa de la Cultura Ecuatoriana, Núcleo del Guayas en 1978. En este estudio, Michael anota, "A pesar de los esfuerzos actuales que analizan el rol de la mujer en Latinoamérica, hay solo información mínima disponible sobre la mujer ecuatoriana [...] el propósito de esta disertación, de esta manera, es llenar este vacío” (vi). 
Me parece fundamental observar, en este momento, que en la obra crítico-literaria-cultural de Michael Handelsman el pretendido carácter "periférico" de la literatura ecuatoriana se asume como un desafío cosmopolita, crítico y personal: desafío cosmopolita y crítico porque estudiar desde la universidad norteamericana una literatura nacional "pequeña" como la ecuatoriana suponía el cuestionamiento de una mirada académica y cultural hegemónica. Aún hoy en día -y no me imagino cómo habría sido esta situación hace treinta o cuarenta años-, la producción literaria de ciertos países como España, México, Brasil y Argentina; o las miradas comparativas regionales y otras trasatlánticas y mundiales, terminan invisibilizando y subordinando la especificidad cultural y literaria de los países más pequeños. Michael observa:

En EEUU, donde en la actualidad hay todo un énfasis en consolidar las particularidades en nombre del World Literature, World History, World Geography, corremos el riesgo de desplazar a todos los (Juan) Rulfos habidos y por haber ya que supuestamente toda América Latina es un conjunto de países pequeños con literaturas pequeñas donde seguimos satisfaciendo nuestra curiosidad por lo "exótico" y, en el proceso, seguimos, cultivando los excesos y las arbitrariedades de un colonialismo siempre en acecho, como enseñó José Martí en Nuestra América en 1891 (2011, 9).

En este sentido, una de las consecuencias de declararse como "ecuatorianista" en la academia norteamericana es, en cierto sentido, marginalizarse, quedarse en la periferia de los circuitos dominantes de producción, circulación y consumo del saber universitario de ese país.

La "pequeñez" de la literatura ecuatoriana es, vista así, el producto de una marginalización exótica que responde a mercados internacionales dominantes, modas académicas en boga y relaciones económico-culturales Norte-Sur desiguales. El trabajo crítico-literario-cultural de Michael, autor de más una docena de estudios monográficos y libros editados, y un centenar de artículos, reseñas y publicaciones misceláneas, cruza aquí sus caminos con el del gestor y promotor cultural. Frente al marginamiento y desconocimiento de la literatura ecuatoriana en la universidad norteamericana; e inclusive, entre los mismos ecuatorianos, Michael emergerá como "un suscitador de la cultura”, como bien lo hubiera llamado Benjamín Carrión. Así lo avala su trabajo como co-fundador y presidente de la Asociación de Ecuatorianistas, fundada en Kentucky en 1987; como guía inspirador de nuevas 
generaciones de críticas y críticos ecuatorianistas y latinoamericanistas; y como promotor de nuevos estudios que reivindican las voces femeninas, étnicas, indígenas y afro-ecuatorianas de la literatura y cultura ecuatorianas.

Me gustaría dar testimonio aquí, de forma personal, además, de la gran calidad humana, presencia luminosa y afectiva del hombre de carne y hueso. No hay otra forma de explicar cómo un "viejo zorro" como él, haya accedido a editar y publicar conmigo De Atahualpa a Cuaubtémoc. Los nacionalismos culturales de Jose Vasconcelos y Benjamin Carrión (2015). En la introducción a este estudio, he escrito lo siguiente y lo comparto ahora una vez más: "Michael Handelsman, co-director del proyecto de investigación y co-editor de este libro, acogió la idea de este proyecto de manera inmediata, aportando su gran experiencia y conocimiento, y siendo un lector riguroso e infatigable, así como un compañero de discusión inmejorable" $(2015,26)$. Tu calidad como intelectual y tu trato y compañerismo horizontales, generosos y respetuosos son un modelo ejemplar para mí, querido Michael.

Asumir el carácter "periférico" y "marginal" de la literatura ecuatoriana desde Estados Unidos, hablando otra lengua, estando expuesto a una visión de Latinoamérica como "patio trasero", teniendo mínima información disponible sobre este pequeño país sudamericano, supuso, además del desafío crítico, un desafío personal: convertir la literatura y cultura ecuatorianas en una aventura legítima del pensamiento y la investigación, demostrando que ese "mundo ecuatoriano" podía ser parte también del propio, y que su carácter "periférico" no era más que un estigma, un estereotipo. En Guayaquil y sus autores. Un homenaje a algunos clásicos que no se van (2017), Michael mismo plantea lo dicho en los siguientes términos:

Según mi condición de académico de Estados Unidos, enfocar mi trabajo como docente e investigador latinoamericanista en Guayaquil (o en Ecuador como tal), siempre requiere una especie de defensa de legitimidad académica. Es decir, dedicarse profesionalmente a estudiar con meticulosidad la literatura e historia cultural de una ciudad y un país cuya resonancia es mínima, por lo menos en mi país, siempre resulta conflictivo puesto que uno se ve obligado a insistir en la pertinencia de tales intereses dentro de una Academia que todavía funciona con su mentalidad colonial (14).

Michael convertirá al país marginal, en definitiva, en el centro de su vida intelectual y afectiva por más de cuatro décadas. Su pasión y de- 
dicación, parafraseando a Aimé Cesaire, nos enseñan que -más allá de los chauvinismos nacionalistas y los romanticismos simplones- "lo ecuatoriano es bello" y que la literatura ecuatoriana tiene valor universal. En el universo de la historia de las ideas de América Latina, la obra crítico-literaria de Michael Handelsman se acerca así, y en mucho, a las reflexiones de Luis Villoro sobre "lo propio" o "auténtico"; o a las ideas de Arturo Andrés Roig sobre el "legado cultural" de la producción intelectual latinoamericana. Esta relectura de "lo propio", "lo local", "lo marginal" en la obra de Michael, sin embargo, antes que afirmar un patrioterismo y esencialismo nacionalistas, supone la descolonización de lo nacional-literario y de nuestras maneras de leerlo y reconocerlo. Descolonizar lo ecuatoriano significa, primero que nada, superar el desconocimiento de lo histórico y culturalmente producido; a la vez que cuestionar el menosprecio y estereotipos con que nos hemos visto y valorado a nosotros mismos y nuestra literatura. En Amazonas y Artistas-y me parece que esta es una constante en todo su trabajo crítico-, Michael indaga con ojo clínico las primeras revistas feministas ecuatorianas, además de la novela, cuento y ensayo escritos por mujeres en el siglo XX, es decir, se pone a leer y estudiar lo que nadie ha leído y estudiado todavía. Él mismo lo explica así: "Este estudio está primariamente preocupado con dos objetivos principales: 1. refutar las afirmaciones tradicionales de que la mujer no ha escrito prosa literaria en el Ecuador; y 2. demostrar que uno de los mayores temas encontrados en sus trabajos ofrecen una perspectiva penetrante del lugar de la mujer en la sociedad ecuatoriana" (vii). Estos dos objetivos, tan nítidamente expuestos en 1976, siguen siendo hoy en día, varias décadas después, totalmente necesarios y contemporáneos. Resulta vergonzante afirmar que no tengamos en el país una historia general de las literaturas femeninas, o de la poesía indígena ecuatoriana; o una mayor producción crítica en general. Sin duda hay mucho por hacer, y este homenaje al intelectual que le ha dado tanto a la literatura y cultura ecuatorianas, debería venir junto con nuestro propio reconocimiento de lo que tenemos todavía pendiente.

En un segundo sentido, descolonizar lo ecuatoriano significa también transformarnos a nosotros mismos en lectores críticos de nuestras letras. Para Michael -y espero leerte bien querido amigo- el desafío más alto de la crítica literaria no está en crear una nueva lectura de una obra, sino en propiciar el nacimiento de un nuevo lector, y sin duda, un nuevo mundo fundado en la convivencia, la complementariedad y el buen vivir. En Gé- 
nero, raza y nación en la literatura ecuatoriana, la obra de Pablo Palacio, Alfredo Pareja Diezcanseco, Eugenia Viteri, Alicia Yánez Cossío, Jorge Icaza, Nelson Estupiñán Bass, Antonio Preciado, Jorge Velasco Mackenzie, Miguel Donoso Pareja, entre otros, es leída como una invitación a repensar de forma contemporánea la existencia de un país plurinacional, multiétnico, conflictivamente mestizo y que tiene una larga tradición patriarcal, sexista y racista. Todo lo cual implica reivindicar la emergencia de nuevas voces en su diferenciación racial, sexual y de género. La literatura ecuatoriana no es una "torre de marfil" inmune a los debates y contradicciones del mundo social contemporáneos, sino todo lo contrario: es una manera de objetivizar el mundo existente, visibilizándolo, y así, plantear la posibilidad de imaginarlo como una realidad-otra. Género, raza y nación en la literatura ecuatoriana, al igual que Guayaquil y sus autores, son obras de compilación que reflejan, además, una suerte de historia personal y profesional del mismo crítico en sus procesos de búsqueda de "pertenencias" y "pertinencias", como él mismo las llama. Hay pues en estas obras una marca testimonial escrita entre líneas: "quisiera creer -nos dice Michaelque mis lecturas también sirven de testimonio puesto que como lector sigo aspirando a ser un testigo de mi tiempo" $(2017,18)$.

No puedo terminar, sin agradecerte, una vez más, querido $\mathrm{Mi}$ chael, por tu guía, ejemplo y apoyo. Muchas felicidades en este merecido homenaje. *

\section{Bibliografía}

Grijalva, Juan Carlos, y Michael Handelsman. 2014. De Atabualpa a Cuaubtémoc. Los nacionalismos culturales de Jose Vasconcelos y Benjamin Carrión. Pittsburgh, Quito: Instituto Internacional de Literatura Iberoamericana / Museo de la Ciudad.

Handelsman, Michael. 1978. Amazonas y artistas: un estudio de la prosa de la mujer ecuatoriana. Colección Letras del Ecuador. Vol. 70-71. Guayaquil: Casa de la Cultura Ecuatoriana, Núcleo del Guayas.

- 2011. Género, raza y nación en la literatura ecuatoriana: hacia una lectura decolonial. Barcelona: CECAL.

- 2017. Guayaquil y sus escritores: un homenaje a algunos clásicos que no se van. Colección del bicentenario de la independencia de Guayaquil. Tomo IV. Guayaquil: Club de La Unión. 